\title{
3D Virtual Worlds: Business and Learning Opportunities
}

\author{
Aasim Munir Dad \\ University of Gloucestershire \\ Park Campus, GL502RH \\ Cheltenham, United Kingdom
}

\author{
Professor Barry Davies \\ University of Gloucestershire \\ Park Campus, GL50 2RH \\ Cheltenham, United Kingdom
}

\author{
Dr Andrew Kear \\ University of Gloucestershire \\ Park Campus, GL50 2RH \\ Cheltenham, United Kingdom
}

\begin{abstract}
Virtual worlds (VWs) are rampant and easily accessible to common internet users nowadays. Millions of users are already living their virtual lives in these worlds. Moreover, the number of users is increasing continuously. The purpose of this paper is to review all the business opportunities on these virtual worlds along with the learning opportunities for the real world companies and business students. This paper clearly and precisely defines the virtual worlds in the context of social networking sites and also aims at discussing the past, present and future of VWs. All the possible business opportunities for the real world companies including advertisement \& communication, retailing opportunities, application for human resource management, marketing research and organizations' internal process management through virtual worlds are critically reviewed here. In addition to the discussion current learning and training opportunities for the real world companies and business students are also reviewed. The paper aims at proving that the VWs are full of business and marketing applications and they could be widely used by the real world companies for effective and efficient business operations.
\end{abstract}

Keywords-Virtual Worlds; Social Networking Sites; Virtual Reality; Virtual Education Environments; Virtual Commerce

\section{INTRODUCTION}

Man is a social animal and he cannot live without society, therefore a social environment around him is imperative to be connected with. In past, man had to go out (Physically) and meet others in order to socialize. However, later, with the technological development man was capable to fulfill his social needs through telephone, internet, online social networking sites (SNS) and online messengers (e.g. MSN and Yahoo) without going out (physically). In the present era of technology world has been transformed from global village to a super global village. VWs are another gift of modern technology for the mankind. These three dimensional VWs are also known as 3D social networks. These 3D VWs provide a simulated real world's environment in which users can do almost all the real world's activities including buying, selling, constructing buildings, dancing, clubbing and even learning and training (Peter, Mark, Aukje and Marcia, 2008).

A large number of users are engaged in these 3D social networks and this population is increasing enormously day by day (Hemp, 2006; Fletcher, 2008; and Melancon, 2011). It is an established fact that the marketer goes where the consumer goes. Therefore, the purpose of this paper is to provide an extensive review of the past studies to sum up all the possible business opportunities within these VWs. Learning and training opportunities for the real world companies and business students will also be focused. In this paper social networking sites (SNS) are defined and then discussed within the context of 3D virtual worlds. History and future prospects of VWs are also reviewed with a view to finding that if the VWs are going to replace Web 2.0 technology before 2020 (Rawlinson, 2007).

Advertisement opportunities in virtual worlds for real world businesses through flagship stores, buying advertising spaces, sponsoring an event and press release of virtual activities are discussed in detail (Kaplan \& Haenlein, 2009). Moreover, virtual worlds are also providing an opportunity for the real world businesses to open retail stores for selling virtual/real products and services or only for promotional objectives (Vrechopoulos, Apostolou \& Koutsiouris, 2009; Kaplan \& Haenlein, 2009). Some other business activities could be done through virtual worlds for instance; application of human resource management, marketing research and internal process management. Educational opportunities are also reviewed in this paper with a view to proving that the real world businesses and business academics can use VWs for learning and training purposes (Boulos, Hetherington \& Wheeler, 2007; Eschenbrenner, Nah \& Siau, 2008; Graves, 2008; Ondrejka, 2008; Guru \& Siau, 2008; and Belei, Noteborn \&Ruyter, 2011). Besides the benefits for real world businesses and educational institutes, some risks for them are reviewed.

The next section of the paper provides a detail review of the virtual words, their past, present and future. Furthermore, business and learning opportunities have also been discussed which provide basis to make recommendations and suggestions at the end of the paper.

\section{REVIEW OF 3D SOCIAL NETWORKS}

\section{A. 3D Social Networks}

Boyd and Ellison (2008) articulated that the web-based Social Network Sites (SNS) allow users to create public (open) or semi-public (close) profiles within those networks in which they can get connected with other users and can see, connect or share other users' connections as well. This definition shows three basic characteristics of SNS i.e. (1) making own identity on these sites, (2) connecting with other users and (3) visiting, connecting or sharing other users' connections. In the present era most of the young and middle aged people are busy in interacting and communicating with 
one another on internet. For this, they use social networks e.g. Facebook, Twitter, LinkedIn etc however, all of these mentioned sites are 2 dimensional (2D) web based social networks. Fetscherin \& Lattemann (2008) claimed that 3 dimensional (3D) virtual worlds have provided users with another medium of communication in which besides simple text chatting, voice over IP is enabled and users can do voice chat as well. Hence, interactivity in virtual worlds is more affluent than that of the other 2D web based social networks.

Virtual world is a new development and it is a type of cyber technology. Since man is a social animal and needs a social environment around him to interact with, Virtual worlds have fulfilled the human socializing needs by enabling users to go out and meet others in a virtual environment through their avatars, as a matter of fact users do not go out physically but just in a virtual environment where they are able to visit different places, cities, clubs, hotels, islands, stores and many other simulated to the real world places (Wyld, 2010). These virtual worlds (e.g. Second Life) have all such characteristics of Social Network Sites as are mentioned by Boyd and Ellison (2008), since 3D virtual worlds allow users to create their own identity separately and uniquely through an avatar, users can make list of connections with other users and can see, connect and share other users' connections as well.

Since virtual worlds and other web 2.0 social network sites share basic characteristics therefore, virtual worlds also lie under the definition of Social Network Sites however, there are many differences between web 2.0 social media and 3D virtual worlds (Kaplan \& Haenlein, 2009). A few differences are explained by Kaplan \& Haenlein (2009), between basic web 2.0 social network sites and 3D virtual worlds. Authors explained the communication and interaction among the virtual worlds users (also called Residents) as a real time interaction which is not possible on web 2.0 social network sites (e.g. Facebook, Twitter, Bebo and Hi5) where one user posts the content at one time and it is consumed by other users at some different time when they come online. Moreover, web 2.0 social network sites allow users to create their online identity however, it is limited while, on the other side residents of virtual worlds are able to create their fully customized self-identity through avatar creation and in some cases they can even make avatars' faces resembling to their real life faces. Residents of virtual worlds can even create the body of their avatars exactly like their real life body by adjusting the height, skin colour, hair style and body fat etc. Moreover, 3 dimensional environments of the virtual worlds also distinguish them from web 2.0 social network sites. The restriction free environment of the virtual worlds is providing the real world businesses with huge opportunities to market their business into these emerging channels of communication.

\section{B. Virtual Worlds}

Virtual worlds also known as metaverses, are 3D online environment where every user has his own Avatar which shows his identity and they are online new media where users, through avatar, can move and communicate (speak and chat). Parmentier and Rolland (2009) stated that the number of users on VWs is increasing continuously. According to a research the number is going double every year (Fetscherin \& Lattemann, 2008). (Gartner, 2007) predicted that by the end of year 2011, 80\% internet users would show their presence on virtual worlds. Though the forecasted number of users has not shown its presence but another careful research has asserted that in year 2018 there would be about one billion users of VWs (Renaud \& Kane, 2008).

\section{Some Important Concepts About Virtual Worlds}

Chesebro (1985) determined that any 'definition' should focus on the unique, exceptional and core elements of the defined thing. However, if all the available (till 2008) definitions of the virtual worlds were analyzed, it would be found that they do not fulfill the basic requirements of 'definition' (Bell, 2008). Bell (2008) opines that the term 'virtual world' is defined by the academics and media differently as per their own understanding and requirement. These definitions are somehow contradictory to each other.

Koster (2004) declared Persistence and Numerous Participation as the essential characteristics of virtual worlds and posited that virtual worlds are virtual spaces where participants represent themselves through avatars. Castronova (2004) determined that these are the computer based environments which could be used by a large number of users simultaneously. If both definitions are analyzed scrupulously, number of dissimilarities will be observed (Bell, 2008). In Koster's (2004) definition of virtual worlds the element of technology was thoroughly missing, though these virtual worlds base entirely on technology and their existence is impossible without it. Castronova (2004) tried to fill this gap but at the same time two characteristics of virtual worlds i.e. persistence and numerous participation were missing in his definition (Bell, 2008). Bell (2008) further critically reviewed the definition by Castronova (2008) and stated that this definition is pointing towards simple chat rooms and hence difference between virtual worlds and chat rooms becomes vague.

Reviewing the prior definitions and indicating the gap between them Bell (2008) defined virtual worlds more precisely. Bell (2008) defined virtual world as a technology based electronic environment where groups of people can interact through avatars at the same time. This definition of Bell (2008) mentions all the attributes of VWs that were missing in the definitions by Koster (2004) and Castronova (2004). Bell (2008) mentioned the element of people in his definition very clearly which was also not obvious in the previous definitions and without presence of people VWs are just like vacant data warehouses. Schroeder (2008) maintained a similar view to that of Bell (2008). Schroeder (2008) defined virtual worlds as an online social place where people, in great number, go overtime and experience social interaction simultaneously. Schroeder's (2008) definition seems to fulfill the gap from the previous definitions like that of Bell (2008). Shcroeder's (2008) definition about VWs contain elements of technology (online), human interaction and simultaneousness.

In an essay Toward a Definition of "Virtual Worlds" written by Mark W. Bell in year 2008 Synchronous, Persistent, Network of People, Represented by Avatars and facilitated by networked computers are the described characteristics of virtual worlds. Bell (2008) argued that these unique characteristics are present in real virtual worlds which 
make them different from traditional social networks and video games.

Sivan (2008) also defined virtual worlds from a slightly different angle. Sivan (2008) argued that 'Real Virtual Worlds' must need to be the combination of $3 \mathrm{D}$ worlds, Community, Creation and Commerce and that is what he called 3D3C (3D, Community, Creation and Commerce). Researcher further explained these elements and described 3D world as a place where through roving camera users can see a world inside these environments (e.g. avatars, houses, cars, land, sky, sun, wind, gravity, water and fire). Community is defined as a place where man, being a social animal, fulfils his social needs by communicating and interacting with others around him. This sense of communication was removed from our society since man started using technology (emails, SMS etc). However, real virtual words are providing this sense of community where users through avatars communicate and interact with each other (Sivan, 2008). Researcher explained about the $2^{\text {nd }} \mathrm{C}$ of $3 \mathrm{D} 3 \mathrm{C}$ and argued that real virtual worlds provide users with an opportunity of creation and experimentation through which users can learn and enhance their knowledge and experience. Commerce element of this definition is explained as real virtual worlds provide opportunities to earn money. Users can earn by doing business activities or through employment opportunities (Sivan, 2008). Some of the virtual worlds which can be viewed by 3D3C prism are WOW, IMVU, Penguin, Second Life, Active Worlds, Sony Home and Google Earth. Messinger, Stoulia \& Lyons (2008) agreed with Sivan (2008) and argued that social networking (community), creating virtual items (creation) and then selling or buying these items (commerce) is the three main features which make any online $3 \mathrm{D}$ world a real virtual world.

\section{Present and Future of the Virtual Worlds}

Virtual worlds are emerging very rapidly and have been doing so since 1990 (Messinger et al. (2008). Today we have a long list of virtual worlds with us. There were a few users in the beginning; however participation is increasing day by day with the rapid growth in technology, greater broadband access with high speed and lower prices (Messinger et al., 2008). Organizations are considering virtual worlds as fields of opportunities; therefore it is necessary to describe the current situation of the virtual worlds and future predictions about them. In this section, present and future of the virtual worlds is discussed briefly.

The number of virtual world users that are registered has reached around 671 million globally, and their disbursements are approximately around 1.8 billion dollars on virtual assets in the third quarter of 2009 (Kzero, 2009). The interest of people in virtual worlds is increasing globally and most recent figures indicate that over 800 million users have registered their account on virtual worlds (Kzero, 2010). Residents of Second Life traded in virtual items worth of 150 million dollars during the third quarter of 2009 (Linden, 2009). This increasing interest has instigated the virtual worlds to focus on various segments such as children, education, adults and special interests of individuals. Daley (2010) stated that VWs will become a necessity for enterprises with various branches, scattered vendors and large numbers of teleworkers.
OECD (2011) revealed that $70 \%$ of all the users of virtual worlds are mainly engaged in VW entertainment and games. This percentage should be carefully inferred as virtual world offer many other applications besides games and entertainment. Some of the users of VWs play games and engage in entertainment, whereas others join lectures and simulations, or participate in research. Kids World is the second largest targeted group with approximately $26 \%$ and $3 \%$ with socializing, and $1 \%$ with workspace worlds. Moreover, users who belong to the age group of 11 to 35 year olds spend an average of 20-25 hours per week in Virtual worlds.

Renaud and Kane (2008) stated that there will be one billion individuals who will be using Virtual worlds by 2018 . In 2009, there were already more than 90 million individuals in Habbo Hotel, 20 million in Cyworls and 13 million in SL. Multinationals, for instance, Adidas. BMW, and Vodafone, are already developing commercial activities in virtual worlds (Parmentier and Rolland, 2009).

\section{E. Background and History of Virtual Worlds}

According to Nood \& Attema (2006) the virtual world is not as novel a concept as it was in the past. It is as old as "Dreaming". There are two kinds of worlds from the beginning: primary world and secondary world (Auden, 1968). The primary world is the world in which a man can feel or see by using his sensory organs, whilst secondary world is the world of a man's imagination. Man always, consciously or unconsciously, imagines many things in his mind. Computerized virtual worlds were initially played as 3D video games only. VWs are also known as Massively Multiplayer Online Games and different terms are being used synonymously, e.g. Massively Multi-Player Online Role Playing Games (MMORPGs), Multi-User Online Virtual Environments (MUVEs), and Networked Virtual Environments (NVEs). Instead of using virtual worlds just for entertainment purposes, users are now using them for social interaction amongst one another in their daily routines (Wyld, 2010). The number of users of these worlds is increasing day by day and it seems that Gartner's (2007) prediction will become true. According to DFC intelligence the world's gaming market was $\$ 67$ billion in 2012 and it is expected to grow up to $\$ 82$ billion in 5 years. In the past, video games were less interactive, single player oriented and users were of a young age. Nonetheless, now virtual worlds are highly interactive, multi-players can interact instantaneously and the users belong to groups of all ages (Adolph, 2011: ITU Telecommunication Standardization Bureau, 2011).

Today's virtual worlds are more developed, interactive and collaborative; therefore, there are hordes of opportunities for different disciplines of life (Barnes and Mattsson, 2008). 3D virtual worlds are commonly categorized into two forms, game oriented and free form virtual worlds (Bainbridge, 2007). Game oriented virtual worlds, e.g. World of War craft, are only used for gaming purposes. Avatars are bound to wear some specific items to play within that environment. In game oriented virtual worlds users usually play with computercontrolled characters and try to win the levels of the game just to get pleasure or entertainment. For this purpose users might have to purchase some virtual items to make him powerful in the game to win the level. Free form of virtual worlds (e.g. 
Second Life) are totally different in nature, as users are not there to play games but are free to perform most of their real life activities. Free form VWs are more close to the real world; they are also known as open virtual worlds (Messinger et al., 2008). People buy and sell different kinds of applications, such as virtual apparels for their avatars, lands, islands, virtual vehicles and many more items. They can do many activities within these virtual worlds that are more simulative than the real world.

\section{F. Parents of Virtual Worlds}

Sivan (2008) argued that real VWs came into being by the happy marriage of two technology based concepts. Sivan (2008) posited that father concept of the virtual world is 'Virtual Reality' and mother concept is 'Gaming Worlds'. However, these worlds are not based merely on these two concepts but also on economy, sociology, business, law, biology, computer science and mathematics (Sivan, 2008). Messinger et al. (2009) agree with Sivan (2008) and believe that online gaming and social network led to today's virtual worlds.

Sivan (2008) defined virtual reality as a computer based environment which provides immersion, interaction and imagination to its users. He further argued that the concept of virtual reality is not new but it has been there since 1962 and was initially used only by the armed forces for training purpose (Sivan, 2008). Sivan (2008) said that if the father of the VW is virtual reality then no doubt the mother is Gaming World. Messinger et al. (2008) also posited that antecedents of the virtual worlds are gaming worlds. Gaming worlds are known to the world since 1978 and the first multi user game was MUD (Multi User Dungeon). MUD is a well-known first multi user game but it was without graphics and was totally based on text (Bartle, 2004). Other well-known gaming worlds are determined below (Bartle, 2004 and Sivan, 2008).

Ultima on-line: It was first 3D graphical gaming world that had registered highest number of users in year 1997. However, it was not free and users had to pay $\$ 9.95$ per month.

EverQuest: Founded in year 1999, it was the 1st game which allowed the user to move along the camera inside the game to see around its avatar. However, in past the user was not provided with this option by other games and avatar's eyes used to be fixed. EverQuest provided the sense of social networks where users played and shared with friends making it a unique game.

Sims on-line: Developed in 2002, it was the first game which allowed users to create the contents. It allowed creativity in $3 \mathrm{D}$ construction.

Word of Warcraft (WOW): Founded in year 2004, the game has millions of users today and every user is charged $\$ 10$ to validate his or her membership. It is a gaming world which not only provides users with gaming opportunities but also with business opportunities.

Second Life: Second Life also known as SL, introduced first time in year 2003, attained immense exposure and media coverage in 2006. This is the 1st gaming world in which users are provided with all in one i.e. community, creation, and commerce. Such kind of gaming worlds come under free-form of virtual worlds (Bainbridge, 2007).

\section{G. Avatar}

In virtual worlds a physical simulated environment is presented through electronic environment where users show their presence by unique characters known as avatars. By means of which, more people interact with one another as well as with the environment. Though an avatar is an electronic presence of the user inside the virtual world, it has much resemblance to a real human being (Melancon, 2011). Taylor (1999) found that users perceive these digital bodies not only as electronic representatives, but also as true bodies controlled through keys under their fingers. Barnes \& Mattsson (2008) defined the word avatar and suggested that it is derived from the Sanskrit word 'Avatara' which means 'Descent' and in general it is refer to the representation of an entity (Jin \& Sung, 2010).

However, today the word 'Avatar' is being used to describe the virtual presence in the virtual worlds. Second Life, a leading virtual world, was the first to use this word for virtual presence of the users (Lee \& Warren, 2007). Each user is free to customize its avatar (social presence) and can shape it to his/her real world's appearance. In addition, it is possible to shape the avatar into any mythical creation. Avatar's each and every part of the body could be customized, e.g. he can increase the height of his avatar to show his real world's appearance. Moreover, skin complexion, eyebrow, hair length, hair style, colour, and chest size etc. could also be customized. In addition, users can show their race and ethnical belonging by customizing their avatar (Jin \& Bolebruch, 2009).

Jin and Sung (2010) focused on avatars by marketers' perspective and argued that these 3D avatars in 3D electronic environments could be used by marketers as a marketing communication tool and as a media for building brands in virtual worlds. And it is no more future as real world companies are already using these Avatars in virtual worlds for the sake of marketing communication and brand-building (Komiak, Wang \& Benbasat, 2005; Holzwarth, Janiszewski \& Neumann, 2006; Komiak \& Benbasat, 2006; and Wang \& Benbasat, 2008). Jin and Sung (2010) further argued that marketers can use avatars in a retail environment to increase its effectiveness.

One of the causes of lack of shoppers trust on online stores was the absence of face to face interaction; however this dispute has been resolved by the presence of avatars in 3D virtual stores (Aldiri, Hobbs, \& Qahwaji, 2010; and Alves \& Soares, 2013).

Online business organizations already had knowledge that human or some kind of apparent relationship is important to build some meaningful relationship with their customers (Qiu $\&$ Benbasat, 2005). Therefore, presence of avatar (face to face interaction) is giving a huge comparative advantage to virtual worlds over traditional web stores. Presence of the Avatar in a $3 \mathrm{D}$ virtual reality retail environment also provides greater satisfaction and better attitude towards the product (Holzwarth, 2006). 


\section{BUSINESS OPPORTUNITIES IN VIRTUAL WORLDS}

Computer based virtual worlds are known since 2003 and they are rampant nowadays (Shen \& Eder, 2009). As mentioned earlier VWs were initially used for merely the gaming purpose however, lately marketers found huge business opportunities in them. Hemp (2006) agreed and argued that a large number of users is engaged with loads of intangible things in VWs e.g. virtual businesses, learning, social groups where residents keep busy in various social activities that range from dancing parties to Christmas celebrations. Therefore, VWs are providing the real world businesses with a gigantic opportunity to market their business inside virtual worlds (Hemp, 2006). Further, Fletcher (2008) reported that in year 2007 there were 14 million accounts alone in Second Life (one of the leading virtual world) while the number of accounts later hit 21.3 million worldwide (Melancon, 2011), as it is an established fact that the marketer goes where the consumer goes. Furthermore, VWs have become extensively important technological tool for the marketers and advertisers to market their product or service in it (Hemp, 2006). Therefore, in order to chase and target the right consumers, marketers began exploring business opportunities within these unique 3D worlds.

One of the research posited that in year $2020 \mathrm{VWs}$ would be as common as world wide web is today (Rawlinson, 2007), a large number of residents attracted businesses to show their presence in these worlds and to target their potential customers. That is why; IBM purchased a private island in Second Life (SL) and showed its virtual presence in April 2006 to promote its brand among its customers and partners (Fletcher, 2008). The IBM's virtual island consisting of 12islands complex including healthcare and Code Island, aimed at showing the demo of the products and to present lectures on software engineering. The real world (RL) companies already present in these virtual worlds are IBM, Dell, Sun Microsystems, Nokia, Sony Ericson, Coca Cola, Microsoft, Toyota, Mercedes, Adidas, Reebok, BMW, L'Oreal, and American Apparel etc. These global companies aim at increasing their brand awareness in VWs to increase the purchase intention of customers in the real world.

\section{A. How Can Real World Businesses Use Virtual Worlds as a Communication Channel?}

The significance of this emerging channel of virtual worlds has been discussed by one of the researches on interactive communication channels (Dad, 2012). Research has pointed out that though the academic researchers did not attach substantial value to this channel, the big brands like Toyota and Reebok have already set off their virtual presence in these worlds. It is thus highly recommended to investigate and explore these VWs in context of their importance for real world businesses and to know that how this emerging communication channel could be used for marketing, branding and advertising the real world products and services (Dad, 2010).

Real world businesses can widely benefit from these VWs especially for advertisement purposes. Kaplan \& Haenlein (2009) stated that virtual worlds could be used in four different ways by real world businesses to advertise their products or services. These four ways of advertising and communication business are briefly explained below:

- Flagship Stores: Virtual presence of Real world companies in VWs can be shown by setting up their virtual flagship stores. In these virtual flagship stores companies can create, sell or test their real world products by the provision of real world's resembled products. One of the big brands from the automotive industry; Toyota already has a virtual store in one of the well-known virtual worlds i.e. Second Life. In past Toyota had launched the virtual edition of its real world Scion $\mathrm{xB}$ model for advertising and testing purpose.

- Buying Advertising Spaces: VWs can be used by the Real world companies for advertising purpose through buying advertising space in virtual malls in the same way as they do in the real world or online web sites e.g. Banners and Billboards etc. There are many companies (e.g. MetaAdverse) working inside the VWs as advertising agencies who buy and sell advertising spaces for the real world businesses and also manage ads for them hence earning huge money. MetaAdverse makes money by letting virtual spaces for advertisement to the real world companies. The real world companies are charged by this company for advertising their brands in VWs. Not only does MetaAdverse advertise the real world's businesses within VWs but also tracks those advertisements to view and provide information regarding their effectiveness. Canada IMAX used this way of communication to advertise the Harry Potter Saga. This way of advertising is proven by research to be cost effective and cheaper as compared to the traditional online advertising on traditional websites.

- Buying Advertising Spaces: VWs can be used by the Real world companies for advertising purpose through buying advertising space in virtual malls in the same way as they do in the real world or online web sites e.g. Banners and Billboards etc. There are many companies (e.g. MetaAdverse) working inside the VWs as advertising agencies who buy and sell advertising spaces for the real world businesses and also manage ads for them hence earning huge money. MetaAdverse makes money by letting virtual spaces for advertisement to the real world companies. The real world companies are charged by this company for advertising their brands in VWs. Not only does MetaAdverse advertise the real world's businesses within VWs but also tracks those advertisements to view and provide information regarding their effectiveness. Canada IMAX used this way of communication to advertise the Harry Potter Saga. This way of advertising is proven by research to be cost effective and cheaper as compared to the traditional online advertising on traditional websites.

- Sponsoring an Event: As mentioned earlier in this paper, the VWs are used for variety of social events i.e. dance parties to religious practices like Christmas and 
Hajj Pilgrimage. Therefore, these events can be sponsored by the real world companies for promoting their real world brands. This method of promotion has already been practiced by one of the British newspapers; Guardian, when it sponsored Secondfest i.e. a music festival inside the Second Life.

\section{B. Press Release of Virtual Activities}

Companies can also give the press coverage to their activities in virtual worlds. Its positive impact has already been proven in research.

There are four different modes of advertising in virtual worlds specifically in SL (Barnes, 2007). These modes include placing a 3D object as Reebok did by placing virtual shoes in its virtual retail store in Second Life (SL), advertising through virtual static billboards, playing ads through multimedia in virtual worlds and through cross-promotion by dancing and camping in virtual malls and casinos etc.

Advertising is always considered crucial for e-marketing promotion (Hemp, 2006; and Sharma, Bakou \& Lijuan, 2012). Other researches also explained the pivotal role of advertisement and promotion for any business and posited that virtual worlds, especially Second Life, could be considered a very favourable interactive communication channel (Hedley, 2006; Sharma et al., 2012; Dad, 2012; Messinger et al., 2009; and Hassouneh \& Brengman, 2011)

For companies, one of the major attractions to use virtual worlds for E-marketing is promotion and branding (Hemp, 2006; Messinger et al., 2009; Dad, 2012; and Sharma et al., 2012). These aforementioned researches have explored the VWs and the business opportunities within these worlds. It is found that advertisement is one of the major benefits that companies can enjoy by using VWs. Since Communication plays imperative role in the success of any business therefore, VWs provide the residents with a unique and highly flexible platform for the interactive communication in addition to a new channel for the effective two sided communication between companies and potential/current customers. Word of mouth has always been an effective form of advertisement therefore; companies can use VWs for brand promotion through word of mouth and blogging.

VWs can also be used by the Real world companies for advertisement and promotion of their brands and vast range of products or services in variety of ways. Some useful means to fulfill the promotional needs of real world companies through virtual worlds are discussed below:

- Real world companies can create their virtual stores or islands within these VWs to promote their brands and vast range of products. Many real worlds' big brands have already shown their presence in these 3D VWs e.g. Dell, Toyota, Adidas etc.

- Since VWs do not have any geographic boundaries so; customers from all around the world could be gathered at one specific place in them where companies can communicate with their potential and current customers simultaneously. This was something impossible without the existence of VWs. Companies can promote their newly launched product or get feedback for their existing products or give virtual product to their customers for test marketing.

- Virtual worlds are much synchronous therefore; an effective communication could be expected between companies and customers.

- A large number of populations could be targeted through virtual worlds therefore; these worlds could be considered as a new interactive communication channel and an alternative to TV and Web advertisements.

- As VWs are cost effective and most interactive communication channel therefore; Small and Medium Enterprises (SME) can benefit immensely by targeting and persuading large number of audience at one time with comparatively meager cost.

- SMEs can also use virtual magazines and newspapers as an alternative to the real world print media. In VWs an ad which normally reaches to 25,000 SL residents on virtual magazines or newspapers costs about $\$ 11$ (Second Style, 2008).

\section{Retailing in Virtual Worlds}

Virtual reality retail stores gave a new concept to the retail industry. Virtual reality retail (VRR) stores are the stores present within these 3D VWs, some of which are freebies and some that are really costly. The virtual world has provided businesses with a new opportunity to market and sell their products. Virtual worlds (e.g. Second Life) are offering an alternative, improved, and quite potential medium to the consumers where they can shop for their virtual lives by paying with virtual money (e.g. Linden Dollars in Second Life). In the same way consumers can also buy for their real lives, but this is just at an introductory stage at the moment (Vrechopoulos et al., 2009).

Unlike web retail stores where many components of traditional retail environments are absent, e.g. Social Factor, the VRR stores that are made up of computer graphics provide a real world simulated environment. VRR stores, like real world stores, are constructed with walls, colours, lighting, instore music, floors, shelves, layout and design. One of the components of a retail store's environment is social presence, i.e. presence of other customers or employees.

VWs are providing real world retailers with a unique opportunity to set up their retail business inside these virtual stores (Kaplan \& Haenlein, 2009), but the concept of retailing in VWs is quite different to that of traditional web 2.0 technology. If traditional online stores are analysed, many discrepancies will be found, for instance the products' images placed on traditional online stores are not true representation of the real product (Keeney, 1999). Moreover, whilst visiting traditional online stores there is a feeling of loneliness and inadequate interaction with other customers (Wang, Baker, Wagner \& Wakefield, 2007). This is not the case with VWs as they provide the customers with a real environment. The retail stores are built with $3 \mathrm{D}$ electronic environment where all the products are $3 \mathrm{D}$ electronic objects that closely resemble the real world product. Moreover, the visitors of VRR stores can also interact with one another (Kaplan and Haenlein, 2009). 
Virtual reality retail stores are the most appropriate representation of the real world stores, which could enhance a company's branding and advertising campaigns. It has also been proven through previous studies that this 3D object placement in VWs has a very positive impact on users' intentions to purchase the same product in real life (Schlosser, 2003 and 2006).

Kukreja and Humphreys (2014) argued that in traditional online stores, goods or services were shown on 2 dimensional flat interfaces where shoppers were not able to see a $3 \mathrm{D}$ view of the product. Moving inside the traditional web stores was known as 'scrolling down or up'. Kukreja and Humphreys (2014) determined that 3D virtual reality retail stores are the substitute of 2D web stores. They are far better than web store and shoppers can move around the stores by walking, flying or running with the help of their avatars. There is no more navigational difficulty in 3D VRR stores which shoppers were facing in traditional web retailing (Kukreja and Humphreys, 2014).

\section{Applications of Human Resource Management (HRM) in Virtual Worlds}

Kaplan and Haeinlein (2009) have discussed in detail that the application of Human Resource Management (HRM) in VWs is possible along with marketing implications. TMP Worldwide Advertising \& Communications is a service provider company that is already involved in recruiting employees from virtual worlds. Recruitment from VWs could be more helpful for technology oriented firms for instance TMobile and eBay because in this way they can have more technology oriented employees.

However, in many cases such recruitment could not be very effective rather many risks are associated with it. A few risks are mentioned below:

- Companies could not generate a large number of populations in VWs as it is a new technology and only a few people are familiar with it.

- Applicants like to be contacted in a more traditional way and they might take virtual recruitment messages as a spam.

- There is a risk of fraud for the companies as they cannot see the real person behind the avatar.

Besides many risks companies can still use VWs for recruitment process. It is recommended that companies should not conduct interviews in VWs though they can post advertisements for vacant positions at any relevant event in virtual worlds.

\section{E. Marketing Research in Virtual Worlds}

Another interesting application of the virtual worlds for real world businesses is to use them for marketing research. There are two major reasons to use VWs for marketing research. It costs very low as compared to the marketing research in real world (Kaplan and Haenlien, 2009). Secondly, a large number of consumers ready to be queried, analyzed and understood could be approached at a single platform
(Messinger et al., 2009). 33\% reduction of cost while conducting research in virtual worlds is already proven (Kaplan \& Haenlein, 2009). Companies are currently researching in VWs to observe the attitude, motivation and behaviour of the residents.

Companies are also researching in VWs for product testing and then modification on the basis of feedbacks they receive (Messinger et al., 2009). For instance, Toyota got its virtual island in Second Life where it sells virtual Toyota car for 300 Linden Dollars which costs about 1 real U.S dollar to the customer after which the customer drives and shows it off to his/her virtual friends and then customizes that car as per his/her choice and need. The customer then gives feedback to real life Toyota engineers. Later in compliance with the customers' feedback the company modifies the real world's model. Another example of test marketing is discussed by Kaplan and Haenlein (2009) when Starwood Hotels \& Resorts, a real world hospitality company, decided to build a new building for their Hotel in real world, it first built the virtual building of the proposed design in Second Life and then invited Second Life residents to visit it and give feedback. Later, the company made many modifications in its real world's design on the basis of resident's feedback in Second Life.

Hence real world companies are highly recommended to use VWs for market research, testing and innovation.

\section{F. Internal Process Management}

Kaplan \& Haenlien (2009) posited that virtual worlds can be used to manage the internal processes of companies e.g. virtual meeting with employees \& business partners, and also for knowledge sharing. Cases of Cisco, IBM and Crown Plaza Hotel chain should be analyzed by the real world businesses to review how these companies managed their internal processes through virtual worlds (Kaplan \& Haenlien, 2009). Cisco has built two virtual islands in Second Life where its employees are provided with an opportunity for formal meetings. Moreover, Cisco has also provided its employees with virtual code of conduct. Similarly, IBM is managing its internal processes through Second Life. It has twenty four islands inside this virtual world. One of the greatest real world hotel chains known as Crown Plaza Hotel has also established its virtual presence in Second Life where it offers customers to book the meeting rooms in virtual Crown Plaza hotel in exactly the same way as they do in real world in United States, England and Switzerland.

These examples could be the benchmark for other real world companies for they can also manage their internal organizational processes through VWs in almost no time at very cheap cost. If a company's CEO has to meet his partners, with the help of VWs he needs not to travel all the way around the world wasting money and time. He can meet his partners in VWs with very effective time and cost. Real world companies are highly recommended to review the above mentioned cases and adopt virtual world technology as a core business application to reduce the cost and time for internal processes management. 


\section{G. Risk and Challenges for Real World's Businesses in virtual Worlds}

Along with many benefits there are certain risks which companies might face while setting up their business in VWs. Some of the risks and challenges for real world companies in virtual worlds discussed by the academic researchers (Hemp, 2006; Kohler, Matzler, \& Fuller, 2009; ) are mentioned below.

- There could be some technological constraints for all the organizations considering to show their presence in VWs but do not have up to date computer systems. It is evident that VWs need updated hardware and software to run. So, it could be a big challenge for organizations to jump in virtual worlds before updating their computer systems.

- Virtual worlds have some technological issues like sudden breakdown while using them which could cause data loss for the companies. However, VWs are getting more sophisticated day by day and this problem does not seem to be faced by users in near future.

- Another risk for the companies in virtual worlds could be the recruitment of an employee whom they do not know at all in real world, who could be any one else behind his or her avatar and thus could damage company's brand name in virtual worlds.

- Companies cannot sign a contract within VWs as law codes are not yet completely formulated and implemented.

\section{LEARNING AND TRAINING POSSIBILITIES IN VIRTUAL WORLDS}

Porter, Weisenford \& Smith (2012) mentioned that in a few recent years many companies have joined virtual worlds to train their employees as VWs provide them with a very cost effective environment for training. Virtual worlds provide a simulated real world's environment where users can do almost all the real world activities including buying, selling, constructing buildings, dancing, clubbing and even learning and training. Many universities and institutions including Harvard University have already built virtual campus inside these metaverses.

Besides many other challenging objectives engagement, interactivity, experimentation and idea generation remain the most challenging for the education sector and even these objectives became more challenging and imperative after the introduction of online course formats (Brenda, Nah \& Siau, 2008). Though to meet these challenges, instructors from education sector have already used, analyzed and examined Wikis and Blogs (Guru and Siau, 2008) but these technologies were not as interactive as 3D virtual worlds (Brenda et al., 2008). In 3D virtual worlds residents are free to interact and engage with one another; moreover they are enabled to create any kind of space they imagine, hence they can perform many experimental activities (Brenda et al., 2008).

Virtual worlds are not fruitful for businesses merely but also for many other fields like hospitals, armed forces and educational sectors. Researchers have explored the usefulness of virtual worlds in educating students through modern and innovative ways (Shen and Eder, 2009; Wagner, 2008; Sarah,
2009; and Belei et al., 2011), distance learning and also for medical and health education (Boulos et al., 2007). In VWs students can go in virtual class rooms where they can interact with one another via text and voice chat options; moreover, they can share and submit assignments using file transfer option. It has been proven through research that VWs could possibly be used by medical, health trainers and libraries in novel ways (Boulos et al., 2007). If used for education and training purposes, VWs would be highly beneficial. Some of the advantages are as follows (Brenda et al., 2008):

- VWs provide the students with a risk free environment for learning where they can share knowledge at very low cost.

- VWs provide the residents with enhanced collaboration and communication where not only can they communicate in real time but also experience a sense of real presence (through avatars) which was absent in traditional internet based learning.

- VWs have not only been credited for providing high engagement where users can learn more with less mental efforts but also for enhancing interest and motivation towards learning.

- Moreover, in VWs institutes can arrange visits of students to all those environments and situations not possible to be visited in real environment, such as a place already vanished in a disaster or a situation perilous to be visited or experienced in real life.

At first IT converted Stone Age world into global village and now this dramatic development and change in IT and internet has transformed this global village into a super global village. Now companies do not base merely in a single town, city or country but they spread their business all around the globe. At present though companies have employees from all around the world belonging to different cultures and countries but still they want to train them all at equal standards. Porter et al. (2012) discussed Veteran Health Administration's (VHA) Disaster Emergency Medical Personnel System (DEMPS) whose employees are geographically scattered however, DEMPS needs to treat and train all the employees equally so that they could perform unanimously as a team moreover; organization also needs its employees to be trained for some real situations that could not be created unless a real disaster happens. Therefore, Porter et al. (2012) examined virtual worlds for two years to test whether these metaverses provide an ideal required environment where DEMPS can train all its employees even if they are geographically scattered. Researchers undertook a study and found that virtual worlds provide an environment which ideally addresses all the challenges, since the employees can get together at one virtual place where they can communicate, collaborate and learn at same standards and patterns, besides it is possible to create variety of scenarios and settings where employees can experience and learn how to handle such situations if confronted with in real world.

\section{A. Virtual Worlds in Education}

Virtual worlds are not only providing opportunities for businesses but also to the academics and students to fulfill their learning and teaching needs (Eschenbrenner et al., 2008; 
Boulos et al., 2007; Belei et al., 2011; and Shen \& Eder 2009). Academics have always been trying to achieve engagement, interaction, collaboration, experimentation and idea generation as common objectives but it remained challenging to achieve all of them simultaneously (Eschenbrenner et al. 2008). It became rather more difficult after the courses moved to online formats. However, many academics tried to overcome these challenges by means of different online technologies such as Blackboards, Wikis and blogs (Guru and Siau, 2008) but still there are many barriers in achieving these objectives by using the above mentioned technologies.

However Eschenbrenner et al. (2008) noticed that these fore mentioned common objectives could be achieved online by using 3D virtual world technology. Guru and Siau (2008) supported virtual world as a potential place for learning as many users can simultaneously log in from different locations of the world and interact with one another at same time. Researchers further argued that these virtual worlds also provide their users with an opportunity to create a customized environment which fulfils their demands of a particular course work (Eschenbrenner et al., 2008). In these VWs either simulating real world's environment could be created to interact and explore, or an entirely new environment could be built to achieve engagement, interaction, collaboration, experimentation and idea generation objectives (Eschenbrenner et al., 2008). Researchers additionally motivated all the users to visit the Second Life Education Wiki and the Second Life education (SLED) Listserv to get to know about the educational opportunities in the Second Life (SL). Guru and Siau (2008) agreeing with Eschenbrenner et al. (2008) posited that schools and colleges can go beyond the conversational mode of teaching by using virtual worlds where students could learn more effectively by enhancing their practical experiences within these VWs.

Wagner (2008) also wrote about the learning and teaching experience in virtual worlds especially in Second Life (SL). He arranged a course called 'Virtual organization and global teamwork' in Second Life and assigned a task to each group of 5 students. Each group was given U.S \$12 i.e. equal to 3,000 Linden dollars and then was asked to build virtual companies and generate the revenue. Wagner (2008) argued that teaching and learning experience of both students and teacher was more than expected. Students produced interesting work through this task which demonstrates their high level of explicit and tacit learning. Moreover, they also generated revenue through their virtual activities on second life though the generated revenue was not enough, as the exchange rate between Linden Dollars and U.S dollars is not that high and on top of it that activity was just for short span of time. Wagner (2008) had a great teaching-learning experience in virtual world thus he concluded that these worlds are offering a unique platform where teaching-learning objectives could be achieved effectively. Moreover, virtual worlds are offering a unique environment which is potential for multi-disciplinary courses. Wagner's (2008) study confirms Guru and Siau's (2008) study in which they proclaimed that VWs could be a source to improve the quality of learning experiences. Guru and Siau (2008) posited that the users' perception of control leads them to get engaged within the environment more easily therefore, virtual worlds are more suitable places to get students and instructor involved in it to practice their theoretical knowledge into practical experience.

Along with Wagner (2008), Eschenbrenner et al. (2008) also mentioned some of the opportunities on hand for education sector in Second Life. Eschenbrenner et al. (2008) opined that simulations and visualizations that are not feasible in reality; are the top ranked capabilities of virtual worlds which could be integrated to fulfill educational purposes. Moreover, virtual world environment fosters innovation and real time communication which encourages educational opportunities within these worlds (Eschenbrenner et al., 2008). Researchers further cited Second Life (2008) as the most suitable 3D world for educational activities. Eschenbrenner et al. (2008) referred to some major features of Second Life which could foster educational activities in it. These features include distance learning facilities, simulation along with interaction and visualization opportunities. In addition, SL could be used for virtual training, seminars and conferences. Virtual worlds could also be used as land of experiments where new ideas could be tested and security could also be assured by purchasing private islands for experimentation purposes (Second Life, 2008 cited in Eschenbrenner et al. 2008). Boulos, et al. (2007) also approved the Eschenbrenner et al. (2008) investigation about the potential of Second Life for educational purposes and argued that many virtual conferences have already been held or going to be held in Second Life. The above quoted examples evidently prove that virtual worlds and especially free from virtual worlds like Second Life could provide another platform for learning.

Shen \& Eder (2009), like the fore mentioned researchers, investigated these immersive virtual worlds and tried to explore their potentiality for educating students. Their research demonstrated that along with many other activities virtual worlds are providing a useful platform for learning. In this study researchers aimed at investigating the students' intention of using VWs for fulfillment of their educational needs. Shen \& Eder (2009) tested Technology Acceptance Model (TAM) and tried to find out the intention of those students who are already using Second Life in MIS courses. The research determined that if students are well expert in computing and have computer playfulness, their 'perceived ease of use' fosters their intention to use Second Life.

\section{B. Use of Virtual Worlds in Marketing Courses}

The above discussion about uses of VWs for education purposes demonstrates that the virtual world is useful only for the students studying computing, information system or gaming but not for the business students. It poses as if merely computing and information system students need their theoretical principles to be applied in practical field. Guru \& Siau (2008) claimed that possibility of gaming in virtual world is not an end whereas, this is just a beginning and further development in the VWs would reconceptualise and restructure our entire education system.

It is true that for many decades' business studies especially marketing studies have been focusing on theoretical principles only but ignoring the practical experiences and the development of all those real skills which students would need 
imperatively when they start their career (Belei et al., 2011). Elam and Spotts (2004) argued that it is truly difficult to simulate real marketing situation through textbooks and class room lectures only and this need is really important to be fulfilled for all marketing courses especially for advertisement and brand management.

Belei et al. (2011) argued that though the lecturers have been trying to fulfill this need of students by assigning those projects but still a huge gap between theory and practice persists. Researchers, after careful analysis of virtual worlds, argued that virtual worlds could be used to enhance students' experience, set up a real scenario and provide countless activities for experimental learning. Further arguing researchers determined that using virtual world is an innovative solution to integrate theory and practical experience (Belei et al., 2011).

As virtual world is suitable place for experiments and wide range of experiences therefore, researchers took benefit from it by assigning branding project to undergraduate students and asking them to develop and practice the branding strategies of their particular brand (Belei et al., 2011). Belei et al. (2011) claimed that through this activity students learned how to practice theory into real market. Though use of virtual worlds for academic curricula still has some limitations but overall it could be much useful and beneficial to both students and teachers. At the end Belei et al. (2011) concluded that virtual worlds are useful for business students to enhance their practical knowledge especially for branding and advertising students.

\section{Some Other Examples of Learning Experiences in Virtual Worlds}

As mentioned earlier technology and internet have achieved that level of sophistication and capability which has changed the whole human cognition process (Haeckel, 1988). Educational institutes are also trying hard to synchronize with this level of technological advancement, therefore constantly exploring and adopting new technologies to get the classrooms online (Erickson and Siau, 2003).

Boulos et al. (2007) discussed some examples of training and educating in Second Life. Researchers argued that there are number of medical and health education projects going on in Second Life. Some of the examples discussed by researchers are presented here.

Ohio University Nutrition Game: Ohio University started a training project in Second Life to educate visitors about the fast foods and their impacts on health. This project was named as 'Nutrition Game' in which users were to choose different eating styles for their avatars and they got more points if food caused good impact on the health of their avatars and less or minus points if the eating style did the contrary job. The main objective of this project was to train users to choose the healthy diet plan.

Healthinfo Island: Another example of medical training and education on Second Life discussed by Boulos et al. (2007) is about Healthinfo Island. This island was solely funded by US National Library of Medicine, also known as NLM, with US $\$ 40,000$. Its sole aim was to provide the users with all the required information about health. This project was started in collaboration with Alliance Library System (ALS), the University of Illinois Library of the Health Sciences-Peoria, the Centre Groningen in the Netherlands and TAP information Services. During the project one to one information, health advice and support was provided to the Second Life residents.

Virtual Neurological Education Centre (VNEC): The institutes of UK have also started considering virtual worlds for training and education purposes. Virtual Neurological Education Centre is a virtual education centre developed by University of Plymouth, UK in virtual world whose purpose was to provide the VW residents with information about the neurological diseases, disabilities and their symptoms. Moreover, it aimed at providing the patients suffering from neurological disabilities with a unique platform where they could get support, information and psychoanalysis trainings.

\section{Benefits of Using Virtual Worlds in Education}

If educators adopt VWs into their education systems, many benefits are expected by the researchers. Some of the potential benefits of adopting VWs for education and training purpose are discussed henceforth.

- VWs can play an important role in distance learning system (Boulos et al. (2007).

- Boulos et al. (2007) argued that students could be educated through VWs' game-based learning system which does not cause boredom and keeps them active as well as interactive.

- Many experiments and activities can be done in virtual worlds in almost risk free-environment (Eschenbrenner et al., 2008 and Graves, 2008).

- Students can develop sense of shared learning which gives students more knowledge and confidence about asking questions (Ondrejka, 2008).

- Students can achieve new dimensions of innovations and creativity by having learning experience in Virtual Worlds (Goral, 2008).

- Conway (2007) argued that VWs can bring attractiveness in online courses for all the interested students since they would be interacting with avatar which gives the sense of presence of a teacher.

- Boulos et al. (2007) determined that in virtual world students can communicate in real time by means of text and voice chat, they can also see one another in avatar shape which increases their sense of presence in real environment.

- VWs could be very beneficial for old and disabled people who can not move easily from their place but are curious to quench their thirst for knowledge (Boulos et al., 2007).

- Mikropoulos (2001) administered an experiment in which it was found that participants put more efforts and show less engagement and learning while performing a task in real life however, it is totally 
opposite in virtual reality worlds where they showed more engagement, gained more knowledge with less efforts and less mental stress. Eschenbrenner et al. (2008) also argued that more attention and engagement could be achieved while performing task in virtual worlds as compared to doing the same in real world.

- Eschenbrenner et al. (2008) argued that by using VWs teachers can teach the courses into a different environment than that of the classroom moreover; they can offer the students a visit to those simulated places which no more exist in the real world e.g. a place that has already been destroyed by a natural calamity.

\section{E. Issues and Challenges to Use Virtual Worlds in Education}

Along with the benefits of using VWs for education and training purposes there are some challenges and issues too. A few of these issues and challenges are discussed below.

- It is difficult to determine in which scenario VWs can be of more value to the learners than the traditional education system (Mantovani, Castelnuovo, Gaggioli and Riva, 2003).

- It is difficult as yet for the educators to determine how these VWs could be utilized in making their education system more effective (Mantovani et al., 2003).

- One of the issues faced by the students in Wagner's (2008) study was the repetitive crash down of system during lab experiments.

- Mantovani et al. (2003) and Dickey (2005) mentioned cost as an issue in adopting virtual worlds for educational purposes. Whenever new technology is considered to be adopted in education sector the main issue has always been the cost issue (Schultze, Hiltz, Nardi, Rennecker and Stucky, 2008) therefore, Eschenbrenner et al. (2008) argued that it could be another issue for the educational institutes to adopt VWs for training and education purpose. Though VWs could be used freely but for experiments and virtual campuses institutes need islands. So the issue could be the cost of purchasing a virtual island or the cost of maintaining an island (Eschenbrenner et al., 2008).

- Non-verbal communication has always been important for human beings, Dickey (2005) argued that it is imperative in traditional classroom environment for students and teachers however, Graves (2008) determined that though avatars present some body language but that does not match with chat or voice so it is just meaningless therefore, virtual classrooms also check the learning process owing to an absence of nonverbal communication which surely exists in traditional classrooms.

- Eschenbrenner et al. (2008) determined that high system performance and high bandwidth power is required to run these virtual worlds however, it is not necessary that every student could have these facilities in his/her home.
- Graves (2008) put forward that keeping an eye on virtual world residents is difficult and it is quite possible that students who use it for educational purposes could deviate from their track and get involved in disruptive and unethical activities. Researcher further explained that it happened with the students of Ohio University and Woodbury University as they were found engaged in virtual shooting and disruptive and hostile activities.

- Eschenbrenner et al. (2008) argued that all those students who are not expert in using virtual worlds can become a nuisance for the teachers by prolonging the scheduled period for the project.

- Wagner (2008) mentioned that the cost issue is not merely a problem for the universities in running projects in VWs but also for students. Though virtual worlds are free to use but if the students have to build something there, which is part of their assigned class project, they have to pay for it.

- Guru and Siau (2008) highlighted another challenge in adopting virtual worlds for education and training. They argued that there are many virtual worlds present today therefore it is necessary for educators to review all these worlds and decide which one should be adopted and at which stage to full fill their objectives.

\section{RECOMMENDATIONS}

As a result of this review paper, there are many recommendations for the real world companies, academics and students from business schools around the world. All the recommendations and suggestions derived from this paper are given below:

- All those real world companies who are using interactive communication channels must consider virtual worlds as new interactive media for advertising (Dad, 2012) since these VWs are described as much cheaper advertising media than the other web based interactive communication channels (Kaplan and Haenlein, 2009).

- Companies should set up virtual flagship stores in VWs for promotion by sponsoring an event in virtual world or through press release of their activities in VWs.

- Companies can use these virtual worlds as a new point of sale where they can sell their products through retail stores.

- Virtual worlds are also highly recommended for service industry where many consultancy companies can set their virtual offices for consultancy. Through these worlds companies can target customers from different countries at a very low cost.

- The tourist companies are also recommended to promote different destinations of the world by making 3D cities on virtual islands simulated to the real world tourists' destinations. 
- All the real world companies investing a huge amount on their Research \& Development departments should focus VWs as a place of innovation and product testing.

- As mentioned earlier in literature section, Small and Medium Enterprises (SME) can immensely benefit from VWs as a cost effective and most interactive communication channel.

- SMEs should utilize virtual magazines and virtual newspaper as an alternative to the real world's print media.

- Though in literature section, application of human resource management has also been reviewed but still companies are recommended to be very careful while recruiting through VWs because employers cannot see behind the avatar and they could be deceived.

- Real world companies can use virtual worlds as a place for market research and product testing in the same way as Toyota and Starwood Hotels \& Resorts had done (Messinger et al., 2009; and Kaplan \& Haenlein, 2009).

- Real world Companies should consider virtual world companies for internal process management where they can meet their partners and employees living in the other corner of the world. It would be very cost effective for them.

- All those companies who want to jump into the virtual worlds are highly recommended to consider their organizational technological structure as virtual worlds need highly upgraded computer systems to run smoothly.

- Companies should also be very careful while making any contract within these worlds as they are not protected by real world's law as yet.

- Virtual worlds are highly recommended for marketing academics and they should assign projects to their marketing students within these worlds.

\section{LIMITATIONS AND FUTURE RESEARCH DIRECTIONS}

Though this review paper is very helpful for companies and academics but it is not free from limitations. One of the major limitations of this research is the fact that it is based on literature review of the past study and no parallel original research has been done. Moreover, different business opportunities are discussed in this short paper instead of focusing on one single opportunity. There are many virtual worlds today but in this paper main focus was Second Life only which is another limitation of this research.

Therefore, it is recommended first to work on these research limitations in future studies. Original research should be done instead of reviewing literature only. And one business opportunity in virtual worlds should be discussed and explored in detail instead of discussing many business opportunities in one short paper. Researchers are also recommended to explore virtual worlds in the context of any specific industry as Dad
(2012) did by exploring interactive communication channels in the context of FMCG industry in United Kingdom; therefore, future researchers should also explore advertising activities in virtual worlds in the context of FMCG or any other industry. In this way a more focused outcome could be achieved which would be more useful for the specific practitioners or academics. Last but not the least, other virtual worlds should also be explored along with Second Life.

\section{CONCLUSION}

Surely, marketer goes where consumer goes and it is proven in the literature reviewed above that the population of the virtual world is growing day by day and it is posited that in year 2020 virtual worlds would be used in the same way as web 2.0 is being used today. In the above review it is proven that virtual worlds are kind of social networks and they got opportunities for real world businesses to use them as a new interactive communication channel which is more cost effective than the traditional interactive communication channels i.e. websites etc. Moreover, these virtual worlds are also very fertile for the application of HRM, marketing research and internal process management as they provide very productive platform for experiments, research \& development, product testing and innovation therefore, these worlds could facilitate real world businesses and academics simultaneously. Academics and students can also use virtual worlds for multi purposes especially for distance learning and conducting experiments. Marketing academics can assign projects to their students on virtual worlds which would be definitely very cost effective and enhancing learning experience as virtual worlds provide a simulated real environment.

Along with many benefits virtual worlds pose some risks too for businesses and academics which they should consider before jumping into these worlds. However, overall this review paper shows that virtual worlds are very useful and beneficial for both academics and businesses and risks are ignorable as compared to the advantages therefore, the academics and businesses are highly recommended to use virtual worlds performing their academic and commerce activities.

\section{REFERENCES}

[1] Auden, W. H. (1968). Secondary Worlds: Essays. Random House.

[2] Barnes, S.J. (2007). Virtual Worlds as a Medium for Advertising. ACM Data Base, Special Issue on Virtual Worlds, November, 2007 (in press). Retrieved on 21 September, 2013, from http://delivery.acm.org/10.1145/1320000/1314244/p45-

barnes.pdf?ip=195.195.4.154\&id $=1314244 \&$ acc $=$ ACTIVE $\% 20$ SER VIC E\&key=C2716FEBFA981EF104A4C70614E4B5CE216D0D76C62E35 $69 \& \mathrm{CFID}=279898759 \& \mathrm{CFTOKEN}=46298607 \& \_\mathrm{acm} \_=1389098487$ _dd2f4146c39a9af0fbafbf1792fe0c54

[3] Barnes, S. J. \& Mattsson, J. (2008). Brand value in virtual worlds: Ann axiological approach. Journal of Electronic Commerce Research, 9 (3), 195-206.

[4] Bainbridge, W.S. (2007). The scientific research potential of virtual worlds. Science, 317 (5837), 472-476.

[5] Bartle, R. A. (2004). Designing Virtual Worlds. New Riders Publishing, 2004

[6] Belei, N., Noteborn, G., \& Ruyter, K. D. (2011). It's a Brand-New World: Teaching Brand Management in Virtual Environments. Journal of Brand Management, 18, 611-23. 
[7] Bell, M. (2008). Toward a Definition of "Virtual Worlds". Journal of Virtual Worlds Research 1(1).

[8] Boyd, D. M. \& Ellison, N. B. (2008). Social Network Sites: Definition, History, and Scholarship. Journal of Computer-Mediated Communication, 13 (1) 210-230

[9] Brenda, E., Nah, F. F. \& Siau, K. (2008). 3-D Virtual Worlds in Education: Applications, Benefits, Issues, and Opportunities. Journal of Database Management, 19 (4), 91-110.

[10] Boulos, M. N. K., Hetherington, L., \& Wheeler, S. (2007). Second Life: An overview of the potential of 3-D virtual worlds in medical and health education. Health Information and Libraries Journal, 24 (4), 233-245.

[11] Castronova, E. (2004). Synthetic worlds. Chicago: The University of Chicago Press.

[12] Castronova, E. (2008). Exodus to the Virtual World: How Online Fun is Changing the Reality. United States, Palgrave Macmillan

[13] Chesebro, J. (1985). Definition as rhetorical strategy. The Pennsylvania Speech Communication Annual, 41

[14] Conway, C. (2007). Professor Avatar. Inside Higher Ed. Retrieved December, 23, 2013, from http://www.insidehighered.com/views/2007/10/16/conway

[15] Dad, A.M. (2012). Interactive Communication Channels and Their Appropriateness for the FMCG Business. International Journal of Management and Business Research, 2 (3), 253-269.

[16] Dickey, M.D. (2005). Three-dimensional virtual worlds and distance learning: Two case studies of Active Worlds as a medium for distance education. British Journal of Educational Technology, 36 (3), 439-451.

[17] Elam, E.L.R. \& Spotts, H (2004). Achieving marketing curriculum integration: A live case study approach. Journal of Marketing Education, 26 (1), 50-65.

[18] Eschenbrenner, B., Nah, F. F.-H., \& Siau, K. (2008). 3-D Virtual Worlds in Education: Applications, Benefits, Issues, and Opportunities. Journal of Database Management, 19 (4), 91-110.

[19] Erickson, J. \& Siau, K. (2003). e-ducation. Communications of the ACM, 46(9), 134-140

[20] Fetscherin, M. and Lattemann, C. (2008). User acceptance of virtual worlds. Journal of Electronic Commerce Research, 9 (3), 231-242.

[21] Fletcher, M. (2008). "Virtual Worlds", Revolution, pp. 54-57.

[22] Gartner. (2007). Gartner says 80 percent of active internet users will have a "Second Life"' in the virtual world by the end of 2011, April 24, Retrieved on 30 November, 2013, from www.gartner.com/it/page.jsp?id $1 / 4503861$

[23] Goral, T. (2008). Sizing up Second Life. University Business, 11(3), 6064

[24] Graves, L. 2008. A Second Life for higher ed: A virtual world offers new opportunities for teaching. US News and World Report 2008, Retrieved on December 1, 2013, From http://www.usnews.com/articles/education/e-learning/2008/01/10/asecond-life-for-higher-ed.html

[25] Guru, A., \& Siau, K. (2008). Developing the IBM I Virtual Community - iSociety. Journal of Database Management, 19 (4), 1-13

[26] Haeckel, S.H. (1998). About the nature and future of interactive marketing. Journal of Interactive Marketing, 12 (1), 63-71.

[27] Hemp, P. (2006). Avatar-based marketing, Harvard Business Review, 84 (6), 48-56.

Haenlein, M. \& Kaplan, A.M. (2009). Flagship Brand Stores within Virtual Worlds: The Impact of Virtual Store Exposure on Real-Life Attitude toward the Brand and Purchase Intent. Researche et Applications en Marketing, 24 (3), 57-79.

[28] Haenlein and Kaplan (2009). Flagship Brand stores within Virtual Worlds: The Impact of Virtual Store Exposure on Real-Life Attitude toward the Brand and Purchase Intent. Recherche et Applications en Marketing, 24 (3), 57-78

[29] Hassouneh, D., \& Brengman, M. (2011). Virtual Worlds: A gateway for SMEs toward internationalization, Journal of Brand Management, 19 (1), $72-90$
[30] Hedley, D . ( 2006 ). Conquering new worlds - Virtual marketing to virtual consumers . Euromonitor International, Retrieved on 28 September, 2013, from http://www.euromonitor.com/conqueringnewworlds-virtual-marketing-to-virtual-consumers/article

[31] ITU-T Technology Watch Report (2011), " Trends in Video Games and Gaming", September 2011, Retrieved on 6 November, 2013, from http://www.itu.int/dms_pub/itu-t/oth/23/01/T23010000140002PDFE.pdf

[32] Jin, S. A. \& Bolebruch, J. (2009). Avatar-Based Advertising In Second Life: The Role of Presence And Attractiveness of Virtual Spokespersons. Journal of Interactive Advertising, 10 (1) 51-60.

[33] Keeny, R. L. (1999). The Value of Internet Commerce to the customer, Management Science, 45 (4), 533-542

[34] Kohler, T., Matzler, K. \& Fuller, J. (2009). Avatar-based innovation: using virtual worlds for real-world innovation",Technovation, 29, 345 407

[35] Koster, R. (2004). A virtual world by any other name?. Message Retrieved on $1^{\text {st }} \quad$ November, 2013, from http://terranova.blogs.com/terra_nova/2004/06/a_virtual_world.html

[36] Lee, R. (2007). Meet the hottest products of 2007: AOL names the most buzzworthy items of the year. $A B C$ News, Retrieved on 6 November, 2013 , http://abcnews.go.com/Business/Webcast/story?id\%C2\%BC4026337\&p age $\% \mathrm{C} 2 \% \mathrm{BC} 1$

[37] Mantovani, F., Castelnuovo, G., Gaggioli, A. \& Riva, G. (2003). Virtual Reality Training for Healthcare Professionals. Cyber Psychology \& Behavior, 6 (4), 389-395

[38] Melancon, J. P. (2011). Consumer profiles in reality vs fantasy-based virtual worlds: implications for brand entry. Journal of Research in Interactive Marketing, 5 (4), 298-312.

[39] Messinger, P. R., Stoulia, E. \& Lyons, K. (2008). A Typology of Virtual Worlds: Historical Overview and Future Directions, Journal of Virtual Worlds Research, 1 (1)

[40] Messinger, P. R., Stroulia, E., Lyons, K., Bone, M., Niu, A., Smirnov, K., \& Perelgut. (2009). Virtual Worlds - Past, Present, and Future: New Directions in Social Computing. Decision Support Systems, 47, 204-228.

[41] Mikropoulos, T. A. (2001). Brain activity on navigation in virtual environments. Journal of Educational Computing Research, 24 (1), 1-12

[42] Nood, D. \& Attema, J. (2006). EPN report: Second Life - the Second Life of virtual reality. Retrieved on 3 November, 2013, from http://www.ecp.nl/sites/default/files/EPN_report_The_Second_Life_of_Virtual_Reality_-_2006_October.pdf

[43] Ondrejka, C. (2008). Education unleashed: Participatory culture, education and innovation in Second Life, In K. Salen (Ed.), The Ecology of Games: Connecting Youth, Games, and Learning, The John D. and Catherine T. MacArthur Foundation Series on Digital Media and Learning (pp. 229-252), Cambridge, MA: The MIT Press.

[44] Parmentier, G. \& Rolland, S. (2009). Consumers in Virtual Worlds: Identity Building and Consuming Experience in Second Life. Recherche et Applications en Marketing, 24 (3), 44-55

[45] Peter, R., Mark, B. Aukje, T. \& Marcia, L. (2008). Face to Face with White Rabbit-Sharing Ideas in Second Life. New Zealand: Victoria University of Wellington.

[46] Porter, E., Weisenford, J. \& Smith, R. (2012). A Journey Through the Design of a Virtual Learning Environment. The Public Manager, 41 (2), 64-68.

[47] Rawlinson, L. (2007). Virtual worlds: The next Facebook?. CNN.com, Retrieved on December 18, 2013 from http://edition.cnn.com/2007/TECH/08/07/virtual.living/

[48] Renaud, C. \& Kane S.F. (2008). Virtual Worlds Industry Outlook 2008 2009 Technology Intelligence Group, Retrieved on 21 November, 2013, from http://blog.techintelgroup.com/2008/08/announcing-thetig-virtualworlds-industry-outlook-2008-2009.html

[49] Sarah, D. F. (2009). Worlds of Wisdom. E Learning Age, pp. 14-15.

[50] Second Style. (2008). Advertise, Retrieved on 23 November, 2013, from http://www.secondstyle.com/advertise.html

[51] Schlosser. (2003). Experiencing products in the virtual world: The role of goal and imagery in influencing attitudes versus purchase intentions. Journal of Consumer Research, 30 (2) (2003), 184-198 
[52] Schlosser. (2006). Learning through virtual product experience: The role of imagery on true versus false memories. Journal of Consumer Research, 33 (3), 377-383

[53] Schroeder, R. (2008). Defining Virtual Worlds and Virtual Environment. Journal of Virtual Worlds Research, 1 (1)

[54] Schultze, U., Hiltz, S. R., Nardi, B., Rennecker, J. \& Stucky, S. (2008). Using synthetic worlds for work and learning. Communications of the Association for Information Systems, 22, 351-370

[55] Sivan, Y. (2008). The Birth of MPEG-V (MPEG for Virtual Worlds). Metaverse1 (blog), Retrieved on 30 September, 2013, from www.metaverse1.org/2008/02/birth-of-mpeg-v-mpeg-for-virtualworlds.html

[56] Sharma, G., Bakou, L., \& Lijuan, W. (2012). Second Life and EMarketing in an Online Social Network: The Implementation in China Marketing. International Journal of China Marketing, 2 (2), 38-59
[57] Shen, J. \& Eder, L.B. (2009). Exploring intentions to use virtual worlds for business. Journal of Electronic Commerce Research, 10 (2), 94-103.

[58] Taylor, T. L. (1999). Life in Virtual Worlds: Plural existence, multimodalities, and other online research challenges. The American Behavioral Scientist, 43 (3), 436-449.

[59] Vrechopoulos, A., Apostolou, K., \& Koutsiouris, V. (2009). Virtual reality retailing on the web: emerging consumer behavioural patterns. The International Review of Retail, Distribution and Consumer Research, 19 (5), 469-482.

[60] Wagner, C. (2008). Learning Experience with Virtual Worlds. Journal of Information System Education, 19 (3), 263-266.

[61] Wang, L. C., Baker, J., Wagner, J. A., \& Wakefield. (2007). Can a Retail Web Site be Social?. Journal of Marketing, 71 (3), 143-157

[62] Wyld, D. C. (2010). A Second Life for organizations?: managing in the new, virtual world. Management Research Review, 33 (6), 529 - 562. 